\title{
A Study of Service Quality of Nepalese Consultants in Building Projects
}

\author{
Sandip Puri ${ }^{1 *}$, Santosh Kumar Shrestha ${ }^{1}$, Dr. Anjay Kumar Mishra ${ }^{2}$ \\ ${ }^{1}$ Department of Civil Engineering, Pulchowk Campus, IOE, TU, Nepal \\ ${ }^{2}$ Associate Professor, Madan Bhandari Memorial Academy Nepal and Pokhara Universit, Nepal
}

\author{
DOI:10.36348/sjeat.2019.v04i09.001 \\ | Received: 06.08.2019 | Accepted: 03.09.2019 | Published: 11.09.2019 \\ *Corresponding author: Sandip Puri
}

\section{Abstract}

Quality in construction sectors is highly dependent upon the services delivered by the respective parties. Since the consulting firms are the one of key resourceful players of any construction projects, the services rendered by the consulting firms performs a vital role before and during the execution of construction for maintaining the quality. This study analyzed the priority order among the success factors determining the quality through AHP (Analytic Hierarchy Process) analysis method after redefining the quality elements of consulting service. The determinants of quality service of consulting service mentioned were configured with SERVQUAL set as the default model. For this study, survey was conducted on 11 public entities who were involved in procuring the consultants for building projects. Public entities were the main sources of primary data collection and published literature, reports and journals were referred as secondary source of infirmities. This research was intended to find out the important determinants of the consulting services, by hierarchizing the service factors for performing the building projects after deriving the relative priority based on the studies on consulting service quality factors. The survey result was produced based on the clients' perspective (58 respondents) with inconsistency value equal to 0.1 . The results of compared analysis between 5 determinants of service quality (Reliability, Responsiveness, Assurance, Tangibles, and Empathy) of Hierarchy 2, the upper layer in the hierarchy of services performance factors and 25 measuring factors of Hierarchy 3 under Hierarchy 2 was presented with inconsistency less than 0.01. The research results," Providing Clear and Quality Drawing/ Documents" and 'Design: Cost Effective, Innovative and Sustainable' were analyzed as important service quality factors. It can be confirmed that consultants performing their service in public entities should have priority to the improvement in drawing quality and effective design rather than the consultant's appearance and relationship with client as an important factor in the quality of service.

Keywords: AHP - Consulting Service - Service Quality - Success Factors - SERVQUAL.

Copyright @ 2019: This is an open-access article distributed under the terms of the Creative Commons Attribution license which permits unrestricted use, distribution, and reproduction in any medium for non-commercial use (NonCommercial, or CC-BY-NC) provided the original author and source are credited.

\section{INTRODUCTION}

In order to remain competitive in developing markets of complex building construction, improving the service quality is a key strategy for consulting firms. As the service quality is directly linked to the client's satisfaction and building long term relationship, it is important to get the whip hand of competition by providing the congruity of the services to the expectation of clients. In this sense, the improvement of the services provided by the consulting firms and the consultants can be seen as an important factor when viewed from the client's side and the efforts made by the consultant is an important variable in building a long-term relationship with the client [1]. The dynamic environment has forced consultants to adapt, in order to cater for the needs of clients and to market [2]. For those consulting firms understanding exactly the client's demand and values, it is the most crucial step in defining and providing the high quality services [3]. SERVQUAL model, built by Parasraman et al. (1988) was tested among the services [3]. SERVQUAL method has five criteria to measure service quality, which implemented with a questionnaire use scales to evaluate respondents' attitude. For this, both qualitative and quantitative factors must be considered in order to evaluate the service quality effectively. In reference to the former studies, the research method applied in this study was firstly to define the determinants and measuring factors of consulting service quality with the theoretical consideration, and then, by applying AHP model to each of the service quality factors, weights for each of the measuring factors were determined. The objective of this research is to derive the success factors 
determining the service quality of Consultants by analyzing the factors with their respective weightage through pairwise comparison matrices so that they may be used in their strategic decision-making.

\section{LITERATURE REVIEW}

The concept of the service quality differs according to the researchers and Garvin and Ghobadian and Simon defined the quality of service viewed by five kinds of approaches such as Transcendent approach, Product-based approach, User-based approach, Manufacturing-based approach and Value-based approach [4]. Quality of service is examined based on the subjective assessment rather than objective measurement. According to the work carried out by Ladhari [5], it is recommended that SERVQUAL model is a good scale to measure service quality in various industries but that is appropriate to choose the most important dimensions of this model that fit to that particular service being evaluated in order to assure reliable and valid results in current business scenario. SERVQUAL model contains five dimension, mainly focusing on human aspects of service providing (reliability, responsiveness, assurance and empathy) and the tangibles of the services. When previous researches are reviewed together, they revealed that the quality attributes differed depending on the type of consulting and it was found that most of them were utilizing a lot the quality dimensions presented in SERVQUAL. This study aims to derive the importance degree among the quality factors using AHP model from the targeted quality attributes of consulting service. AHP is a systematic procedure to procure the optimum option that has the highest degree of importance from all relevant attributes. It includes both subjective and objective approach that forces to think through the service attributes with the help of hierarchy structure. The criteria at a particular level in a hierarchical structure are compared using nine-point numerical scale to define how much more an element is important than other in making pair-wise comparisons and obtaining the judgement matrix [6]. It allows to translate subjective opinions, such as preferences or feelings, into measureable numeric relations.

\section{METHODOLOGY}

Service Quality Elements

SERVQUAL is a mature service quality framework with 5 criteria and 20 sub-criteria, which has been incorporated into customer-satisfaction [7]. But in practical case, there is a need for more studies to find out the quantity of these criteria and sub-criteria. In our study, we used the mathematical model to quantify the criteria based on client's perspective.

AHP model developed by Saaty [8] in the early $1980 \mathrm{~s}$ is the decision-making methodology intended to identify the evaluator's intuition, knowledge and experience through the judgment by the way of Pairwise Comparison of the elements that constitute a hierarchy of decision making. It is to undergo a four-step process such as the hierarchy setting, pairwise comparison of elements, weight estimation, consistency analysis and the synthesis of the relative weight.

\section{Weights of Criteria: Analytic Hierarchy Process (AHP)}

This research is based on more accurate priority weights of determinants and measuring factors, assigned by AHP. Correspondingly, the priority weights are useful for consulting firms to adopt a better strategy while providing the service for improving its service level. There are five major steps in analytic hierarchy process.

\section{Define the Problems and Its Goal}

To obtain more accurate results, the problems should be defined clearly and rational. In this study, the focus was made on "Consulting Service Quality: Based on Clients Perspective".

\section{Hierarchy Structure}

The hierarchy is structured by classifying the goals, criteria (determinants) and sub-criteria (measuring factors) in different hierarchy levels. The most specific elements i.e measuring factors belong to the lower level while the decision making factors or the determinants of service quality in upper level, maintain the hierarchical relationship while different factors of the same layer should maintain the independent relationship each other. In accordance of these principles, the following hierarchy of consulting services quality as in Table-1. 
Table-1: Hierarchy Structure

\begin{tabular}{|c|c|c|}
\hline Hierarchy 1 & Hierarchy 2 & Hierarchy 3 \\
\hline & & $\begin{array}{l}\text { Providing Service at promised time } \\
\text { Having good moral principles }\end{array}$ \\
\hline & Reliability & $\begin{array}{l}\text { Attention for Cost, Time and Quality of Project } \\
\text { Years of Experience } \\
\text { Past Performance }\end{array}$ \\
\hline & & $\begin{array}{l}\text { Frequent Sharing of Progress } \\
\text { Prompt Response to Request and Problems }\end{array}$ \\
\hline & Responsiveness & $\begin{array}{l}\text { Flexible enough to change and variation } \\
\text { Willingness to Help } \\
\text { Prompt Defect Rectification }\end{array}$ \\
\hline & & $\begin{array}{l}\text { Organization Structure for fulfillment of duties } \\
\text { Technical Competency }\end{array}$ \\
\hline \multirow[t]{5}{*}{ Consulting Service Quality } & Assurance & $\begin{array}{l}\text { Understanding the client requirement and project objectives } \\
\text { Confidence in project management } \\
\text { Trustworthy }\end{array}$ \\
\hline & & $\begin{array}{l}\text { Adequacy of Cost Analysis and Estimate } \\
\text { Design: Cost Effective, Innovative and Sustainable }\end{array}$ \\
\hline & Tangible & $\begin{array}{l}\text { Provide Clear and Quality Drawings } \\
\text { Motivated, Competent and Courteous Staff } \\
\text { Neat attire and Appearance of Consultant }\end{array}$ \\
\hline & & $\begin{array}{l}\text { Compliance and Understanding of Clients Brief } \\
\text { Relationship with Client }\end{array}$ \\
\hline & Empathy & $\begin{array}{l}\text { Maintaining Public Relations } \\
\text { Follow-up after initial service } \\
\text { Availability of Consultant }\end{array}$ \\
\hline
\end{tabular}

Hierarchy 1 defines the goal of the research while Hierarchy 2 was based on the five elements of SERVQUAL such as tangibles, reliability, responsiveness, assurance and empathy. For the quality factors of consulting services in Hierarchy 3, the lowertier hierarchy of this study, 25 kinds of service factors were derived based on literature studies.

\section{Pairwise Comparisons of Each Factors}

Pairwise comparisons of hierarchy 2 and hierarchy 3 was done by assigning them relative scores constructing paired matrices. The priority scores with the 9-points scale was marked for pairwise comparison, as shown in Table.

\section{Compute the relative weight of the criteria for each level \\ Using the way of Eigenvalues, the relative weights (Priority Vector) of the decision making factors}

are estimated. It is to obtain the maximum Eigen value in pairwise comparison by the geometric averaging and by normalizing the eigenvectors derived based on it.

Judgment consistency can be checked by taking the consistency ratio (CR) of $\mathrm{CI}$ with the appropriate value in Table-2. The CR is acceptable if it is lower than 0.10. Or else the judgment matrix is inconsistent.

$$
\mathrm{CR}=\mathrm{CI} / \mathrm{RI}
$$

Where,

$$
\begin{aligned}
& \text { CR: Consistency Rate } \\
& \text { CI: Consistency } \\
& \text { Index RI: Random Index }
\end{aligned}
$$


Table-2: Overall Weightage and Priority of Measuring Factors

\begin{tabular}{|c|c|c|c|c|c|}
\hline Hierarchy 2 & Priority & Hierarchy 2 & Priority & Global & $\begin{array}{c}\text { Global } \\
\text { Priority }\end{array}$ \\
\hline \multirow[t]{3}{*}{ (Importance) } & Order & (Importance) & Order & Weight & Order \\
\hline & & Providing Service at promised time $(0.157)$ & 3 & 0.032 & 15 \\
\hline & & Having good moral principles $(0.124)$ & 4 & 0.025 & 20 \\
\hline \multirow[t]{5}{*}{ Reliability(0.202) } & 3 & Attention for Cost, Time and Quality of Project $(0.351)$ & 1 & 0.071 & 4 \\
\hline & & Years of Experience $(0.106)$ & 5 & 0.021 & 22 \\
\hline & & Past Performance $(0.262)$ & 2 & 0.053 & 7 \\
\hline & & Frequent Sharing of Progress $(0.191)$ & 3 & 0.036 & 12 \\
\hline & & Prompt Response to Request and Problems $(0.219)$ & 2 & 0.041 & 10 \\
\hline \multirow{5}{*}{ Responsiveness $(0.187)$} & 4 & Flexible enough to change and variation( $(0.184)$ & 4 & 0.034 & 13 \\
\hline & & Willingness to $\operatorname{Help}(0.106)$ & 5 & 0.020 & 24 \\
\hline & & Prompt Defect Rectification $(0.301)$ & 1 & 0.056 & 6 \\
\hline & & Organization Structure for fulfillment of duties $(0.134)$ & 5 & 0.027 & 18 \\
\hline & & Technical Competency $(0.247)$ & 2 & 0.050 & 8 \\
\hline \multirow[t]{5}{*}{ Assurance(0.187) } & 2 & $\begin{array}{l}\text { Understanding the client requirement and project } \\
\text { objectives }(0.279)\end{array}$ & 1 & 0.057 & 5 \\
\hline & & Confidence in project management $(0.157)$ & 4 & 0.032 & 14 \\
\hline & & Trustworthy $(0.183)$ & 3 & 0.037 & 11 \\
\hline & & Adequacy of Cost Analysis and Estimate( 0.252$)$ & 2 & 0.073 & 2 \\
\hline & & $\begin{array}{l}\text { Design: Cost Effective, Innovative and } \\
\text { Sustainable }(0.252)\end{array}$ & 3 & 0.073 & 3 \\
\hline \multirow[t]{5}{*}{ Tangible $(0.290)$} & 1 & Provide Clear and Quality Drawings $(0.255)$ & 1 & 0.074 & 1 \\
\hline & & Motivated, Competent and Courteous Staff( $(0.169)$ & 4 & 0.049 & 9 \\
\hline & & Neat attire and Appearance of Consultant $(0.072)$ & 5 & 0.021 & 23 \\
\hline & & Compliance and Understanding of Clients Brief $(0.243)$ & 1 & 0.029 & 16 \\
\hline & & Relationship with Client(0.116) & 5 & 0.014 & 25 \\
\hline \multirow[t]{3}{*}{ Empathy(0.119) } & 5 & Maintaining Public Relations(0.192) & 4 & 0.023 & 21 \\
\hline & & Follow-up after initial service $(0.216)$ & 3 & 0.026 & 19 \\
\hline & & Availability of Consultant $(0.234)$ & 2 & 0.028 & 17 \\
\hline
\end{tabular}

\section{Determine Overall Level Hierarchy Weight}

The composite priorities of the overall level of hierarchy weight are then determined by aggregating the calculated weights throughout the hierarchy and criteria.

\section{Data Collection and Analysis}

By conducting the survey targeting 67 government officers involving in building projects, a survey result of total 58 people was produced, excluding 9 people with $\mathrm{CR}$ values greater than 0.1 . As shown in Figure 1, the results of compared analysis between 5 kinds of major factors of Hierarchy 2, the upper layer in the hierarchy of service quality factors and 25 kinds of measuring factors of Hierarchy 3, the lower layer of the hierarchy presented $C R$ values less than 0.1 on all individual units, that are to be trusted and the relative importance and priority for each assessment factor are shown in figures.

\section{Analysis Results of Hierarchy 2}

$\mathrm{CR}$ value of the performance area Hierarchy 2 was 0.01 and, as shown in Figure-1, the relative importance and priority between the major factors were analyzed by order of the tangible (0.290), assurance (0.203), reliability (0.202), responsiveness (0.187) and empathy (0.119). Based on current consulting service, Respondent considered the tangible character as a most important factor to be addressed by the consulting practitioners. This means that consulting practitioners should focus on tangible character more during service period to enhance their service performance.

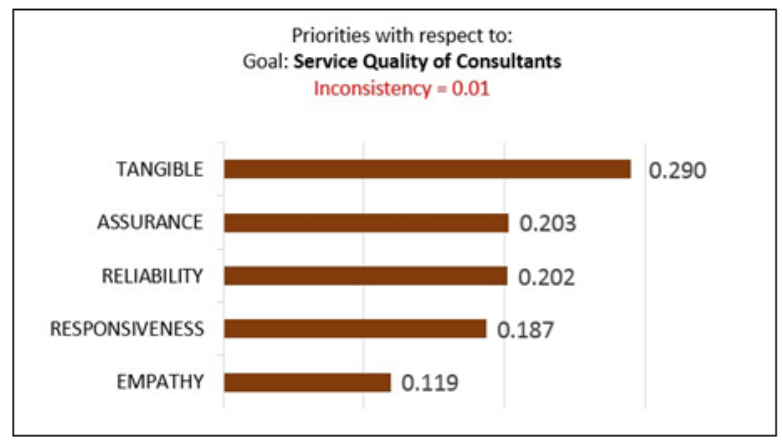

Fig-1: Priorities with respect to Service Quality of Consultants

\section{Analysis Results of Hierarchy 3}

First, as shown in Hierarchy Structure Figure 2 , the relative importance and priority of Reliability measuring factors of Hierarchy 3, was analyzed with ranking order such as 'Attention for cost, time and quality of project (0.351)', 'Past Performance (0.262)', 'Providing Service at Promised Time (0.157)', 'Having good moral principles (0.124)'amd 'Years of Experience (0.106)'. This can be seen that the consultant's character such as the attention for cost, time and quality of projct was regarded more important 
than the years of experience for quality factor of consulting service.

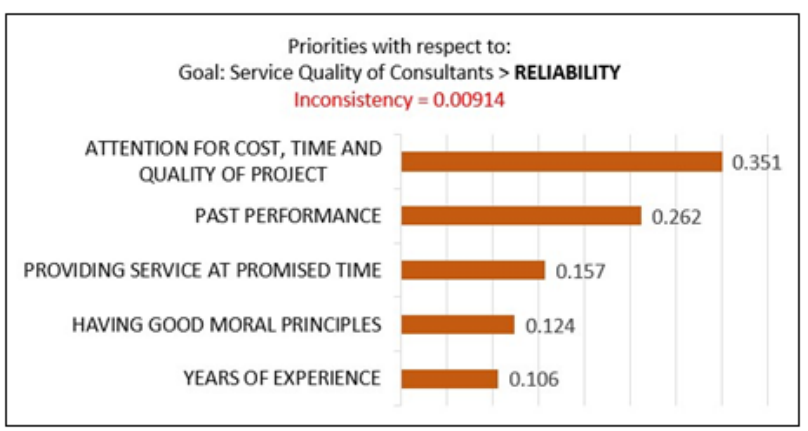

Fig-2: Priorities with respect to Reliability

Second, as the analysis results of Responsiveness factor, the relative importance and priority between measuring factors was rated in the ranking order such as 'Prompt Defect Rectification $(0.301)$ ', 'Prompt response to requests and problems (0.219)', 'Frequent sharing of progress' (0.191)', 'Flexible enough to accommodate change and variation (0.184)'and 'Willingess to Help (0.106)'. To rectify the defects promptly was analyzed to be the most important factor of the consulting service quality factors.

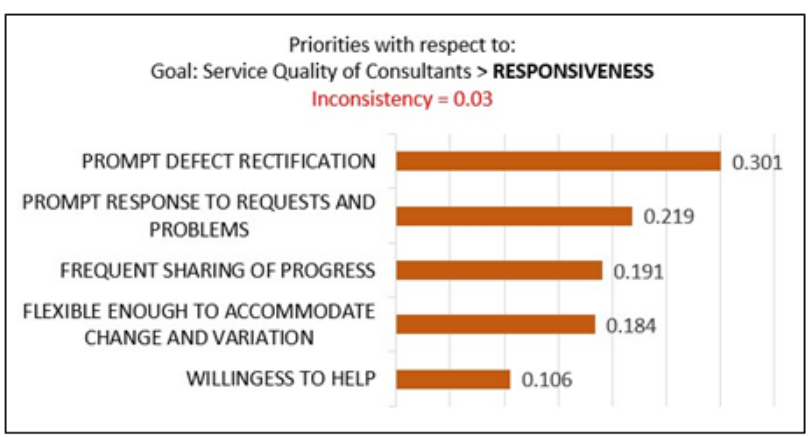

Fig-3: Priorities with respect to Responsiveness

Third, as the results of analysis of Assurance factors, the relative importance and priority between measuring factors were ranked in order of 'Understanding clients requirement and project objectives (0.279)', 'Technical Competency (0.247)', 'Trustworthy (0.183)', 'Confidence in project management $(0.157)$ ' and 'Organization structure for fulfillment of Duties (0.134)'. And it can be seen that the understanding client's requirement and project objectives is important.

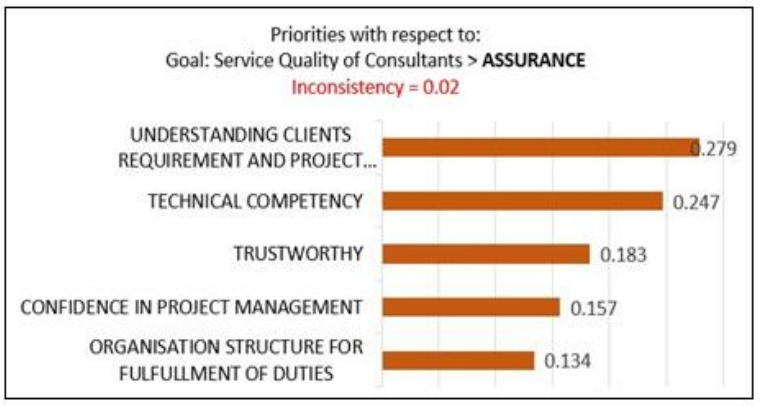

Fig-4: Priorities with respect to Assurance

Fourth, as the results of analysis of Tangible factor, the priority and relative importance between measuring factors were ranked in order of 'Provide clear and quality drawing (0.255)', 'Adquency of cost analysis and estimate (0.252)', 'Design: cost effective, innovative and sustainable (0.252)', 'Motivated, Competent and Courteous Staff (0.169)' and Near attire and appearance of consultant (0.072)', and it was analyzed that the providing clear and quality drawing as being an important factor.

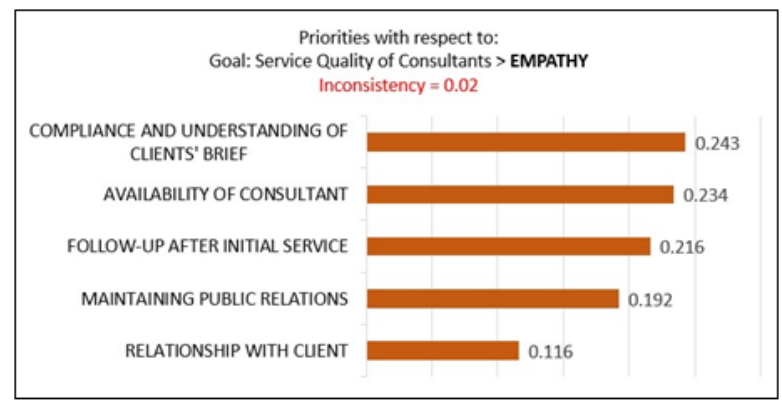

Fig-5: Priorities with respect to Tangible

Fifth, as the results of analysis of Empathy factor, the priority and relative importance between evaluation factors were ranked in order of 'Compliance and understanding of clients brief (0.243)', 'Availability of Consultants (0.234)', 'Follow-up after initial service (0.216)', 'Maintaining Public Relations (0.192)' and 'Relationship with Client (0.116)', and it was analyzed that Compliance and understanding of clients brief an important factor among the underlying factors of Empathy.

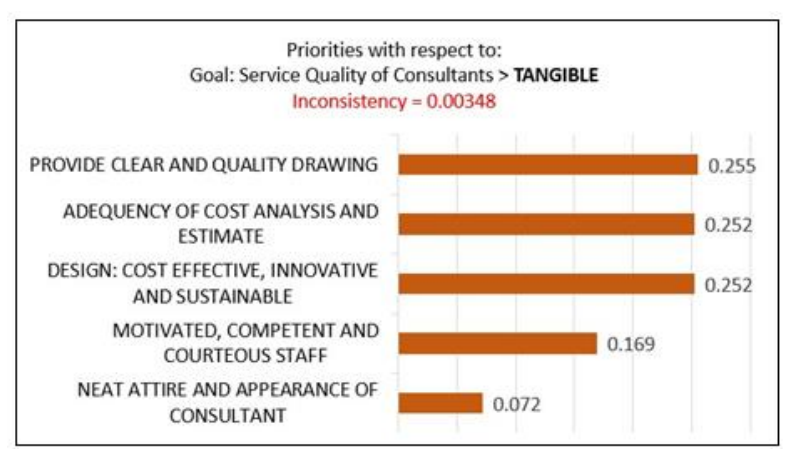

Fig-6: Priorities with respect to Empathy 


\section{Synthesis of the Relative Importance Due to the} Measuring Factors

As the results of comprehensive assessment of the priority and relative importance between the whole measuring factors of service quality of consultants were, as shown in Figure 8, were ranked in the following order of 'Providing Clear and Quality Drawings (0.074)', 'Adequacy of Cost Analysis and Estimate (0.073)', 'Design: Cost Effective, Innovative and Sustainable (0.073)', 'Attention for cost, time and quality of project (0.071)', 'Understanding client requirement and project objectives (0.057)', 'Prompt Defect Rectification (0.056)', 'Past Performance (0.053)', 'Technical Competency (0.050)', 'Motivated, Competent and Courteous Staff (0.049)', 'Prompt response to requests and problems (0.041)' and so on. It can be seen that providing clear and quality drawings and adequacy of cost analysis and estimate were analyzed as important factors among whole quality measuring factors than the relationship with client.

\section{CONCLUSION}

In the construction projects, service of consulting firms plays a vital role for assuring the quality of the delivered services involving both design and construction phase. In this study, we propose AHP method combining qualitative research and quantitative analysis on important measuring factors of the consulting services, by hierarchizing the service factors of each level after deriving the relative priority based on the existing researches on consulting service quality measuring factors. By adjusting service determinants and measuring factors, the research and survey approach has been carried out based on importance survey of public entities. As the research results, "Providing clear and quality drawings" and 'Adequacy of cost analysis and estimate' were analyzed as important service quality measuring factors. It can be suggested that consultants should provide clear and quality drawings along with adequate cost analysis and estimate rather than the maintaining the relationship with client. Although this study presented the findings which suggested the priority by analyzing systematically the quality measuring factors of consulting services, it has the limitation that the study areas were limited to public entities within Kathmandu Valley who published their EOI for hiring consultants in building project through e-GP portal; PPMO.

\section{ACKNOWLEDGMENTS}

The authors are grateful to Tribhuvan University, Institute of Engineering [IOE] and Pulchowk Campus for the technical support during this research project. The authors are also thankful to all the respondents, friends and helpful hands for being a part of this research.

\section{REFERENCES}

1. Shin, D. J., You, Y., Hong, J., \& Lee, S. K. (2015). Study on the effects of follow-up consulting service on perceived reciprocity, corporate trust and relational embeddedness. Indian Journal of Science and Technology, 8(S7), 395-405.

2. Philip, S. (1998). Managment Consultancy: A Handbook for Best Practice1998. Kogan Page Limited, 1 edition.

3. Parasuraman, A., Zeithaml, V. A., \& Berry, L. L. (1988). Servqual: A multiple-item scale for measuring consumer perc. Journal of retailing, 64(1), 12-40.

4. Sang-Bok, S., \& Gi-Jun, S. (2011). Study on the management consulting service quality and customer satisfaction. Business Education, 25:15982.

5. Ladhari, R. (2009). A review of twenty years of SERVQUAL research. International journal of quality and service sciences, 1(2), 172-198.

6. Martínez, J. A., \& Martinez, L. (2010). Some insights on conceptualizing and measuring service quality. Journal of Retailing and Consumer Services, 17(1), 29-42.

7. Li, Y. (2014). Service Quality Measurement Using Fuzzy AHP-Based Approach. JCP, 9(7), 16971703.

8. Saaty, T. L. (1990). How to make a decision: the analytic hierarchy process. European journal of operational research, 48(1), 9-26. 